\title{
COMPARISON OF PRIMARY REPAIR WITH HEALING BY SECONDARY INTENTION FOR THE TREATMENT OF PILONIDAL SINUS, AT A TERTIARY CARE HOSPITAL IN KARACHI, PAKISTAN.
}

1. MBBS, FCPS

Assistant Professor \& Head Department of General Surgery Hamdard College of Medicine and Dentistry.

2. MBBS, FCPS (General Surgery), Assistant Professor

Department of General Surgery Sir Syed College for Medical Sciences for Girls.

3. MBBS, FRCS (Edinburgh), FRCS (Glasgow), FCPS.

Consultant

Department of General Surgery

4. MBBS, FCPS

Assistant Professor

Department of Anesthesiology \& ICU,

Liaquat University of Medical and Health Sciences Jamshoro.

Correspondence Address:

Dr. Hamid Raza

B 15 Samanabad Bhitai Town Qasimabad Hyderabad, Pakistan. drhamidraza1@gmail.com

Article received on: 17/07/2018

Accepted for publication:

$15 / 12 / 2018$

Received after proof reading:

$31 / 07 / 2019$

\begin{abstract}
Muhammad Ghayasuddin ${ }^{1}$, Fareya Usmani ${ }^{2}$, Amtullah Sheikh ${ }^{3}$, Hamid Raza ${ }^{4}$
\end{abstract}
ABSTRACT... The aim of our study is to assess the surgical outcome of healing by primary intention and compare it with primary repair for the treatment of pilonidal sinus. Study Design: Randomized controlled trial. Setting: Tertiary Care Center in Karachi Pakistan. Period: Two years from April 2015 to April 2017. Materials and Methods: 60 patients were divided into two groups by utilizing a Random Allocation Software. All the patients involved in the study signed a duly informed consent. The inclusion criteria were patients who presented to us with a pilonidal sinus and agreed to participate in the study. All the procedures were performed by the same team of surgeons. Patient follow up was bi-weekly at the outpatient. Data were collected in a predesigned proforma with various variables such as patient demographics, clinical findings, treatment option used, postoperative results, complications (if any), healing time, length of hospital stay and time for a return to function among others. The data were analyzed using IBM SPSS version 21.0. A p value of less than 0.05 was considered to be statistically significant. Results: $N=60$ patients were included in the study. There were $n=51$ men $(85 \%)$ and $n=9$ women (15\%). The mean age of patients in group $A$ was $26.45+/-5.81$ years and the mean age of participants in group B was $27.10+/-5.75$ years. Symptoms lasted for $6.52+/-2.03$ days, the most common presenting complaint was pain in $51.66 \%$ of patients followed by discharge in $40 \%$ and swelling in $33.33 \%$ respectively. The mean length of stay at the hospital for both the groups was $4.40+/-2.11$ days $(4.09+/-1.96$ days in group $A$ and $4.85+/-2.33$ days in group $B)$, mean time to return to normal functioning was $17.88+/-8.46$ days $(14.50+/-7.30$ days in group $A$ and $23.80+/-6.50$ days in group $B$ ). The mean healing time postoperatively for both the groups was $39.98+/-24.46$ days $(21.90+/-10.15$ days in group $A$ and $67.30+/$ 9.09 days in group B. Early postoperative infection was found in $n=7(11.66 \%)$ patients, wound necrosis was found in $n=2(3.33 \%)$ patients, and recurrence of the pilonidal sinus was found in $n=3(5 \%)$ of the patients respectively. Conclusion: According to the results of our study primary closure technique provides better outcomes in terms of early return to functioning, shorter duration of wound healing and lower rates of wound infection as compared to excision and healing by secondary intention.

Key words: Healing by Secondary Intention, Open Healing, Pilonidal Sinus, Primary Closure, Surgical Outcome.

Article Citation: Ghayasuddin M, Usmani F, Sheikh A, Raza H. Comparison of primary repair with healing by secondary intention for the treatment of pilonidal sinus, at a Tertiary Care Hospital in Karachi, Pakistan. Professional Med J 2019; 26(8):1306-1310. DOI: 10.29309/TPMJ/2019.26.08.3874

\section{INTRODUCTION}

Chronic trauma from hair follicles most commonly in the area of the natal cleft causes an abnormal cystic infolding to form this abnormal cystic infolding is called a pilonidal sinus. The incidence of pilonidal sinus is 26 per 100,000 and is more common in young males. $44 \%$ of the patients work at jobs which involve prolonged sitting and $38 \%$ report a positive family history of pilonidal sinus. ${ }^{1}$ It presents as a swelling with abscess, cellulitis and sometimes with a discharging sinus. ${ }^{2}$ The infected area is tender and the patient often reports fever as well. ${ }^{3}$ The local tenderness causes hindrance to the patient's daily activities and is an uncomfortable condition for the patient and it may hinder occupational performance as well. ${ }^{4}$ In young adults, a quick and effective treatment of pilonidal sinus is required to minimize morbidity and return to functioning. Therefore, a surgeon's priority is effective relief from symptoms and 
minimal complications of the procedure. ${ }^{4,5}$ However, not all surgical procedures go as planned, leading to postoperative complications, issues surrounding wound healing and treatment failure. ${ }^{1}$ The appropriate treatment for pilonidal sinus is still under debate whether having the wound left open to be healed by second intention or to have it closed by suturing and primary closure. ${ }^{6,7,8}$ The surgeons who prefer primary closure prefer this method of treatment so as to restore the structural integrity of the skin, thus enabling rapid healing and return to normal functioning. The surgeons in favor of open healing argue that in primary closure there is a high rate of recurrence and no significant difference in return to normal functioning, the time duration of wound healing and complications. ${ }^{4,9,10}$ In our part of the world the patients prefer primary repair as there are early recovery period and less number of follow-ups to clinics. To that extent, the aim of our study is to assess the surgical outcome of healing by primary intention and compare it with primary repair for the treatment of pilonidal sinus. The secondary aim of the study is to compare the return to function, recurrence rates, complications, wound healing time and length of stay in the hospital.

\section{METHODS}

The type of study is a randomized controlled trial conducted for a period of two years from April 2015 to April 2017 at a tertiary care center in Karachi Pakistan. 60 patients were divided into two groups $A$ and $B$ with patients undergoing open healing belonging to group $B$ and patients belonging to primary repair in group $A$. The patients were divided into two groups by utilizing a Random Allocation Software. All the patients involved in the study signed a duly informed consent and when the patient was unable to sign the consent their parent or guardian signed the consent. The inclusion criteria were patients who presented to us with a pilonidal sinus and agreed to participate in the study. The exclusion criterion was all the patients who had recurrent pilonidal sinus, spinal dysraphism, and perianal abscess. All the procedures were performed by the same team of surgeons. To avoid mechanical injury to the wound the patients were advised to lie in a prone or lateral position. Dual analgesia was used to control pain and all the patients also received broad-spectrum antibiotics as prophylaxis. Patient follow up was bi-weekly at the outpatient clinic for the first three months and then every two months for up to a year. Data were collected in a predesigned proforma with various variables such as patient demographics, clinical findings, treatment option used, postoperative results, complications (if any), healing time, length of hospital stay and time for return to function among others. The data were analyzed using IBM SPSS version 21.0, independent sample t-test, Wilcoxon sign-rank test and Mann-Whitney $U$ test were used to analyze the data. A p value of less than 0.05 was considered to be statistically significant.

\section{RESULTS}

$\mathrm{N}=60$ patients were included in the study and were equally divided in both the groups. There were $n=51$ men $(85 \%)$ and $n=9$ women (15\%) in the study. The mean age of patients in group A was $26.45+/-5.81$ years and the mean age of participants in group B was $27.10+/-5.75$ years. For other demographic variables refer to Table-l. Symptoms lasted for $6.52+/-2.03$ days, the most common presenting complaint was pain in $51.66 \%$ of patients followed by discharge in $40 \%$ and swelling in $33.33 \%$ respectively. The majority of patients did work that required prolonged sitting in one position or had thick hairs on their skin, the occupations of participants were clerical staff $33.33 \%$ students $36.66 \%$ and cab drivers $15 \%$ respectively. The mean length of stay at the hospital for both the groups was $4.40+/-2.11$ days (4.09 +/- 1.96 days in group A and $4.85+/-2.33$ days in group B), mean time to return to normal functioning was $17.88+/-8.46$ days $(14.50+/$ 7.30 days in group $A$ and $23.80+/-6.50$ days in group $B)$. The mean healing time postoperatively for both the groups was $39.98+/-24.46$ days $(21.90+/-10.15$ days in group $A$ and $67.30+/-$ 9.09 days in group $B$ ). For other clinical variables refer to Table-l. Early postoperative infection was found in $n=7$ (11.66\%) patients, wound necrosis was found in $n=2(3.33 \%)$ patients, and recurrence of the pilonidal sinus was found in $n=$ $3(5 \%)$ of the patients respectively. 


\begin{tabular}{|c|c|c|c|c|}
\hline Variable & $\begin{array}{l}\text { Group A }(n=30) \\
\text { Primary Repair }\end{array}$ & $\begin{array}{c}\text { Group B }(n=30) \\
\text { Healing by } \\
\text { Secondary Intention }\end{array}$ & Total $(n=60)$ & P-Value \\
\hline \multicolumn{5}{|l|}{ Gender } \\
\hline Male & $26(86.66 \%)$ & $25(83.33 \%)$ & $51(85 \%)$ & \\
\hline \multicolumn{5}{|l|}{ Symptoms } \\
\hline Fever & $9(30 \%)$ & $6(20 \%)$ & $15(25 \%)$ & \\
\hline Swelling & $12(40 \%)$ & $8(26.66 \%)$ & 20 (33.33\%) & \\
\hline Discharge & $14(46.66 \%)$ & $10(33.33 \%)$ & $24(40 \%)$ & \\
\hline Pain/Tenderness & $18(60 \%)$ & $13(43.33 \%)$ & $31(51.66 \%)$ & \\
\hline \multicolumn{5}{|l|}{ Complications } \\
\hline Infection & $1(3.33 \%)$ & $6(20 \%)$ & $7(11.66 \%)$ & \\
\hline Necrosis with Superficial Dehiscence & $2(6.66 \%)$ & $0(0 \%)$ & $2(3.33 \%)$ & \\
\hline Recurrence & $3(10 \%)$ & $0(0 \%)$ & $3(5 \%)$ & \\
\hline
\end{tabular}

Table-I. Patients demographics and other characteristics

\section{DISCUSSION}

Various surgeons and specialists in the field have developed a wide variety of procedures for the treatment of pilonidal sinus. The variety of procedures used range from simple excision of the sinus tract followed by healing through secondary intention, curettage, marsupialization, rhomboid muscle flaps, Karydaki's procedure (off midline primary closure), midline primary closure, Limberg technique (z-plasty) among others. . $^{8,11,12,13,14,15}$ In our study we looked at two procedures the primary midline closure technique and excision of the sinus and laying the wound open. The most common outcome desired by both the operating surgeon and patient is rapid healing, decreased complications and early return to normal functioning with minimal pain and requirement of analgesic medications. McCallum et al in their meta-analysis showed that primary surgical closure especially the techniques where the incision is made off midline have improved rates of healing and return to functioning, and the primary closure techniques (midline closure) are associated with an increased rate of recurrence. ${ }^{4}$ In our study we observed that patients undergoing primary closure returned to functioning earlier as compared to the healing by secondary intention group, however, both the groups had no significant difference in terms of length of stay at the hospital. Similar results were shown by McCallum et al and are in agreement with other similar studies. ${ }^{4,16}$

Complications such as wound dehiscence and infection were also found to be more common in primary closure techniques in our study, the midline technique as adopted by us in our study is associated with a higher rate of the aforementioned complications. Recurrence was observed in $5 \%$ of the cases and all of them belonged to the primary closure group. Other similar studies also found that the recurrence rate is higher in the primary closure group. ${ }^{2,4,10,17}$ However, this recurrence rate was not statistically significant. Various researchers compared the effectiveness of primary closure and oblique incision (Limberg technique) and found a mean length of hospital stay of $1.44+/-3$ days and $5.51+/-2.85$ days, Mentes et al observed a $5.6 \%$ recurrence rate in the 18 months follow up period in their study, while Bali et al did not find any patient with recurrence of a pilonidal sinus. ${ }^{18,19}$ In our study we found a $5 \%$ recurrence rate with primary closure and length of stay of $4.09+/$ 1.96 days. Return to normal functioning is also a significant factor which affects the morbidity 
and accounts for the success of primary closure, according to a study by Kaser et al they observed a $49 \%$ complication rate in primary closure and a complication rate of $12 \%$ in the open wound healing group. ${ }^{20}$ According to them both, the treatment methods were fairly similar in terms of their results, recurrence rate, complications, length of hospital stay and return to normal functioning. However, the high complication rate observed warrants attention be given to infection control and factors that might influence infection rates such as wound necrosis and dehiscence. In some patients, infection is unavoidable such as patients with diabetes, widespread systemic infection, poor immune system etcetera. In our part of the world poor hygiene also plays a significant role in infection rates, proper care and daily dressing of the wound, availability of health facilities and patient compliance are also some other important factors. Enriquez Navascues et al in their meta-analysis proposed that the midline closure techniques and radical excision with open healing methods be abandoned by surgeons completely. They advocated the use of off-midline closure technique on the basis of shorter length of stay, lower rates of recurrence and complications. ${ }^{9}$ While other authors such as Emir et al, Gilani et al, and Lorant et al, advocate the benefits of either procedure as both the procedures result in patient satisfaction, low cost and provides early mobility and a lower rate of complication and recurrence.

\section{CONCLUSION}

According to the results of our study primary closure technique provides better outcomes in terms of early return to functioning, shorter duration of wound healing and lower rates of wound infection as compared to excision and healing by secondary intention.

\section{Copyright@ 15 Dec, 2018.}

\section{REFERENCES}

1. DagA, Colak:T, Turkmenoglu 0, Sozutek A, Gundogdu R. Phenol procedure for pilonidal sinus disease and risk factors for treatment failure. Surgery 2012; 151:113-7.
2. Kareem TS. Surgical treatment of chronic sacrococcygeal pilonidal sinus. Open method versus primary closure. Saudi Med I2006; 27: 15347.

3. Theodoropoulos GE, Vlahos K, Lazaris AC, Tahteris E, Panoussopoulos D. Modified Bascom's asymmetric midgluteal cleft closure technique for recurrent pilonidal disease: Early experience in a military hospital. Dis Colon Rectum 2003; 46:12869.

4. Mccallum U, King PM, Bruce I. Healing by primary closure versus open healing after surgery for pilonidal sinus: Systematic review and metaanalysis. Br Med I 2008; 336(7649):868-71.

5. Perruchoud C, Vuilleumier H, Givel IC. Pilonidal sinus: How to choose between excision and open granulation versus excision and primary closure? Study of a series of 141 patients operated on from 1991 to 1995. Swiss Surg 2002; 8:255-8.

6. Toccaceli S, Persico Stella L, Diana M, Dandolo $R$, Negro P. Treatment of pilonidal sinus with primary closure. A twenty-year experience. Chir Ital 2008; 60:433-8.

7. Kirkil C, Boyuk: A, Bulbuller N, Aygen E, Karabulut K, Coskun $S$. The effects of drainage on the rates of early wound complications and recurrences after Limberg flap reconstruction in patients with pilonidal disease. Tech Coloproctol 2011; 15:425-9.

8. Gencosmanoglu R, Inceoglu R Modified lay-open (incision, curettage, partial lateral wall excision and marsupialization) versus total excision with primary closure in the treatment of chronic sacrococcygeal pilonidal sinus: A prospective, randomized clinical trial with a complete two-year follow-up. Int J Colorectal Dis 2005; 20:415-22.

9. Enriquez-Navascues JM, Emparanza Jl, Alkorta M, Placer C. Meta-analysis of randomized controlled trials comparing different techniques with primary closure for chronic pilonidal sinus. Tech Coloproctol $2014 ; 18(: 863-72)$.

10. Mccallum I, King PM, Bruce I.Healing by primary versus secondary intention after surgical treatment for pilonidal sinus. The Cochrane database of systematic reviews. 2007(4): Cd006213.

11. Karydakis GE. Successful treatment of pilonidal sinus after explanation of its causative process. AustN ZI Surg 1992; 62:385-9. Bascom J. Surgical treatment of pilonidal disease. $\mathrm{Br}$ Medi 2008; 336(7649):842-3. 
12. Karaca AS, Ali R, Capar M, Karaca S. Comparison of Limberg flap and excision and primary closure of pilonidal sinus disease, in terms of quality of life and complications. IKorean Surg Soc 2013; 85:236-9.

14. Shabbir F, Ayyaz M, Farooka MW, Toor AA, Sarwar $H$, Malik AA. Modified Limberg's flap versus primary closure for treatment of pilonidal sinus disease: A comparative study. J Pak Med Assoc 2014; 64:1270-3.

15. Enshaei A, Motearefi S. Comparison of two surgical methods, primary closure,and rotational flap, in patients with chronic pilonidal sinus. Glob Health Sci2014; 6(7 SpecNo):18-22.

15. Muzi MG, Maglio R, Milito G, Nigro C, Ciangola I, Bernagozzi B, et al. Long-term results of pilonidal sinus disease with modified primary closure: new technique on 450 patients. Am Surg 2014; 80:4848.

16. Lorant T, Ribbe I, Mahteme H, Gustafsson UM, Graf W. Sinus excision and primary closure versus laying open in pilonidal disease: A prospective randomized trial. Dis Colon Rectum 2011; 54:300-5.
17. Mentes 0, Bagci M, Bilgin T, Coskun I, Ozgul 0, Ozdemir M. Management of pilonidal sinus disease with oblique excision and primary closure: Results of 493 patients. Dis Colon Rectum 2006; 49: 104-8.

18. Bali i, Aziret M, Sozen S, Emir S, Erdem H, Cetinkiinar S, et al. Effectiveness of Limberg and Karydakis flap in recurrent pilonidal sinus disease. Clinics 2015; 70:350-5.

19. Kaser SA, Zengaffinen R, Uhlmann M, Glaser C, Maurer CA. Primary wound closure with a Limberg flap vs. secondary wound healing after excision of a pilonidal sinus: A multicenter randomized controlled study. Int J Colorectal Dis 2015; 30:97103.

20. EmirS, Topuz 0, Kanat BH, Bali I. Sinotomy technique versus surgical excision with primary closure technique in pilonidal sinus disease. Bosn J Basic Med Sci 2014; 14:263-7.

21. Gilani SN, Furlong $H$, Reichardt $K$, Nasr AO, Theophilou G, Walsh TN. Excision and primary closure of pilonidal sinus disease: Worthwhile option with an acceptable recurrence rate. Ir J Med Sci 2011; 180:173-6.

\begin{tabular}{|c|c|c|c|}
\hline \multicolumn{2}{|c|}{ AUTHORSHIP AND CONTRIBUTION DECLARATION } \\
\hline Sr. \# & \multicolumn{1}{|c|}{ Author-s Full Name } & \multicolumn{1}{|c|}{ Contribution to the paper } & Author=s Signature \\
\hline 1 & M. Ghayasuddin & $\begin{array}{l}\text { Conceptualization, Write up, data } \\
\text { collection, literature reveiw, proof } \\
\text { reading. } \\
\text { Literature review, data collection, } \\
\text { write up, analysis proof reading. } \\
\text { Data collection, write up, } \\
\text { analysis, literature review. } \\
\text { Corresponding author, Data } \\
\text { collection, literature review, initial } \\
\text { write up. }\end{array}$ \\
\hline 4 & Fareya Usmani & Hamid Raza & \\
\hline
\end{tabular}

